\title{
Research on Synthetical Production Proration of Deep Gas Well in Xu Jiaweizi Block Considering Multi Influential Factors
}

\author{
Qingbo Zhao \\ Northeast Petroleum University, Daqing, China. \\ Email: lywes@163.com \\ Received January $14^{\text {th }}, 2012$; revised May $3^{\text {rd }}$, 2012; accepted May $12^{\text {th }}, 2012$
}

\begin{abstract}
Xu deep volcanic gas reservoir is typical of complex lithology, severe inhomogeneity, big difficulty to extract. Pressure sensitivity always exists in gas reservoirs. Prorating production is too high or low, causing problems, as for the energy loss, reservoir damage, bottom effusion, thus lowing the gas productivity and affecting development benefit. So it have to research on a new reasonably production proration method considering multi influential factors. It is a reasonably production proration method considering multi influential factors in Xu gas reservoir, with guidelines such as capacity use, pressure draw down, gas recovery rate, water out and throughout water data is reasonably, so we can long term use it to guide gas field exploitation.
\end{abstract}

Keywords: Deep Gas Wells; Multifactor; AOF; Synthetical Production Proration

\section{Preface}

Xu deep gas reservoir is located in Anda territory of Heilongjiang province. It is a volcanic rock gas field of billions of reserves in the domestic, which is the main part of the exploitation of Petrochina daqing natural gas company. At present, the hydrocarbon gas reservoir of xu deep gas reservoir has submited $1193.36 \times 10^{8} \mathrm{~m}^{3}$ of verified geological reserves, including $202.7 \mathrm{~km}^{2}$, of gas that contains six blocks namely Sheng Ping, Xing Cheng, Chang De, Wei Shen 5, Wang Jia Tun deep and Zhao Zhou west. So far Xu deep gas reservoir has invested 30 production Wells and $148.18 \times 10^{8} \mathrm{~m}^{3}$ reserves.

$\mathrm{Xu}$ deep volcanic gas reservoir has a complex lithology and strong heterogeneity which make it difficult to exploit, and there is no successful development experiences so far. According to the existing production wells, edge water or bottom water exists in most gas reservoirs. If the way of exploitation is taken unreasonably, waterflooding will easyly emerges. Gas reservoirs is always pressure-sensitive. Prorating production too high or low, can lead to a series of problems such as energy loss, reservoir damage, andbottom effusion, thus will lower the gas productivity and affect the development benefit. Prorating production of inital gas wells is often 1/4 to 1/6 of AOF, it has certain artificial while lack scientific basis. Most study schemes of optimal prorating production recently only consider the single limiting factors [1], which can't meet the other indexs of developing optimal gas reservoir. So it is necessary to carry out comprehensive researches, determine reasonable method, and control the mining method of gas reservoir. In this way, the gas well production can work in reasonable production, refrain gas reserve from waterflooding. So we can make sure that the gas reservoir has a high recovery degree.

In the realization of the gas field in prorating production, domestic has the following several ways: gas extraction curve method, the optimization method, the material balance method, Production history to legal method, numerical simulation method, experience method and so on [2]. Throughout the present situation and development at home and abroad of the gas well (reservoir) production research, we can know that there are a lot of mature researches for each type of gas reservoir of single well production dynamic analysis and pressure drop change process. To the condensate gas reservoir of oil and gas system in the actual form, seepage flow characteristic, the development of the dynamic and the different production period of optimization research in single well production process are to be further discussed; But for the study of each single well production in optimization constitute research of the whole gas reservoir production configuration is a new field of learning. 


\section{Research on Synthetical Production Proration}

\subsection{Energy Use with Reasonable Production Proration}

The coordination of gas well is refered to joining relationship in the process of gas flow. To make the gas well product stability, in the system of gas well, each connected flow process must be coordinated [3]. The coordination conditions is: 1) the mass flow of each cohesion in the process are equal; 2) the rest pressure of previous process is enough to overcome the pressure consumption of the next process, that is to say, the rest pressure of previous process should be equal to the starting pressure of the next process. Node system analysis is coordinating concept in the development of the application. Gas well node system analysis can be quickly and easily changed the system parameters to realize the dynamic simulation of the gas well and be convenient to gain the coordinate gas well production.

With bottom hole for node is the most commonly used method of analysis. Set the bottom hole node make the whole gas well system as Lifting oil tubing, ground line two parts, As shown in Figure 1 shows. The part of node inflowing is the seepage for gas, with inflows dynamic (IPR) curve to describe. From the central of gas layer to ground separator, the pressure drop is the sum of lifting oil pipeline pressure drop and the ground pressure drop. The upstream and downstream pressure of node is:

Node into the pressure:

$$
p_{w f}=\sqrt{p_{r}^{2}-a q_{s c}-b q_{s c}^{2}}
$$

Node outflow pressure:

$$
p_{w f}=p_{\text {sep }}+\Delta p_{\text {tubing }}+\Delta p_{\text {ground pipeline }}
$$

In the coordinating chart draw the inflowing dynamic curve, and the outflowing dynamic $\left(p_{w f}-q\right)$ curve, It is also IPR curve and OPR curve, make the two curve be drawed in the same coordinate figure, The intersection point of the two curve is the coordination bottom-hole flowing pressure and production of the gas system, As it is shown in Figure 1.

\subsection{Gas Recovery Rate with Equilibrium Production}

The determination of single well control reserves occupies an important position in the development process of gas reservoir, single well production of Gas well is the important parameters in analysising and planning gas field development [4]. When Matching production need to achieve a balanced recovery speed, ensure reasonable development, long-term and stable production of gas field.

The single well control reserves calculation formula:

$$
\frac{Q_{g}}{G_{p}}=A-B G_{p}
$$

Recoverable reserves:

$$
G_{R}=\frac{A+\sqrt{A^{2}-4 B Q_{g a}}}{2 B}
$$

\subsection{Safe in Prorating Production with Carry Liquid Flow}

Critical carry liquid output:

$$
q_{\mathrm{c}}=2.5 \times 10^{4} \frac{A p u_{\mathrm{c}}}{\mathrm{ZT}}
$$

The parameters that influence the critical flow rate and the critical flow velocity are: Gas to liquid density, Gas to liquid surface tension, gas compression coefficient, oil tubing cross-sectional area, pressure, temperature, gas production and liquid production and so on. But in the given production situation, Calculated point temperature and pressure decided other parameters [5].

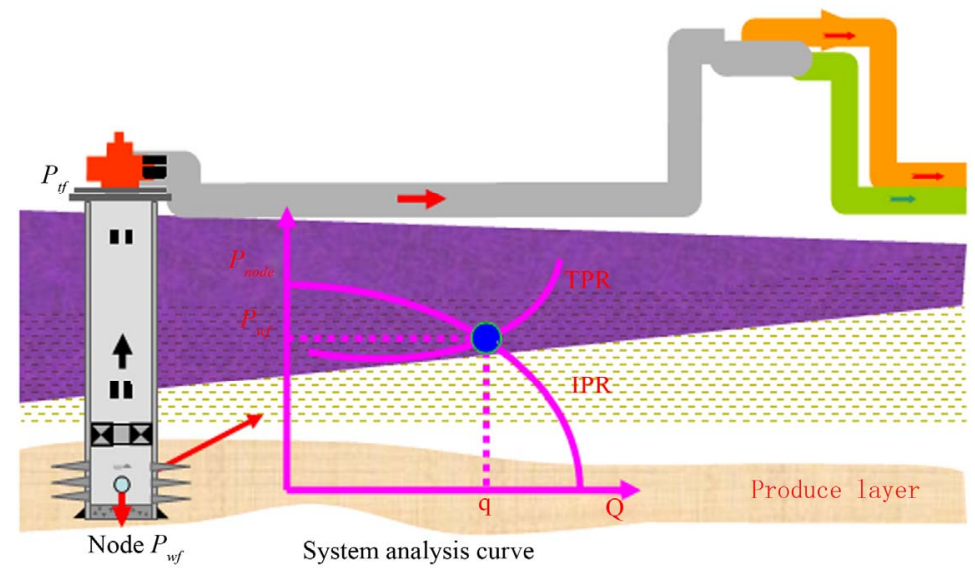

Figure 1. Compatible production general schematic drawing of gas well. 
Temperature and pressure for the influence of Carry critical liquid flow is the opposite (see Figure 2), From the bottom of the well to the top of the well, temperature drop make the critical fluid flow value increases, but pressure drop make the critical fluid flow value decrease, so from the bottom of the well to the top of the well, the increase and decrease of the critical value depends on the influence of the temperature and pressure which accounts for a leading role. From the bottom of the well to the mouth of the well, Because of the temperature of the lower strata is higher, he temperature of the initial gas loss is little, and the pressure loss is bigger. At the same time, the pressure is the leader factor.

Above the analysis about typical data in Xu Jiaweizi, we can conclude that the control conditions of carry critical liquid flow may be in bottom, or in top. Calculate the carry critical liquid flow of the bottom well and the top well, and then converted to the carry critical liquid flow under the standard condition, the larger value can be as the critical fluid production of the whole well.
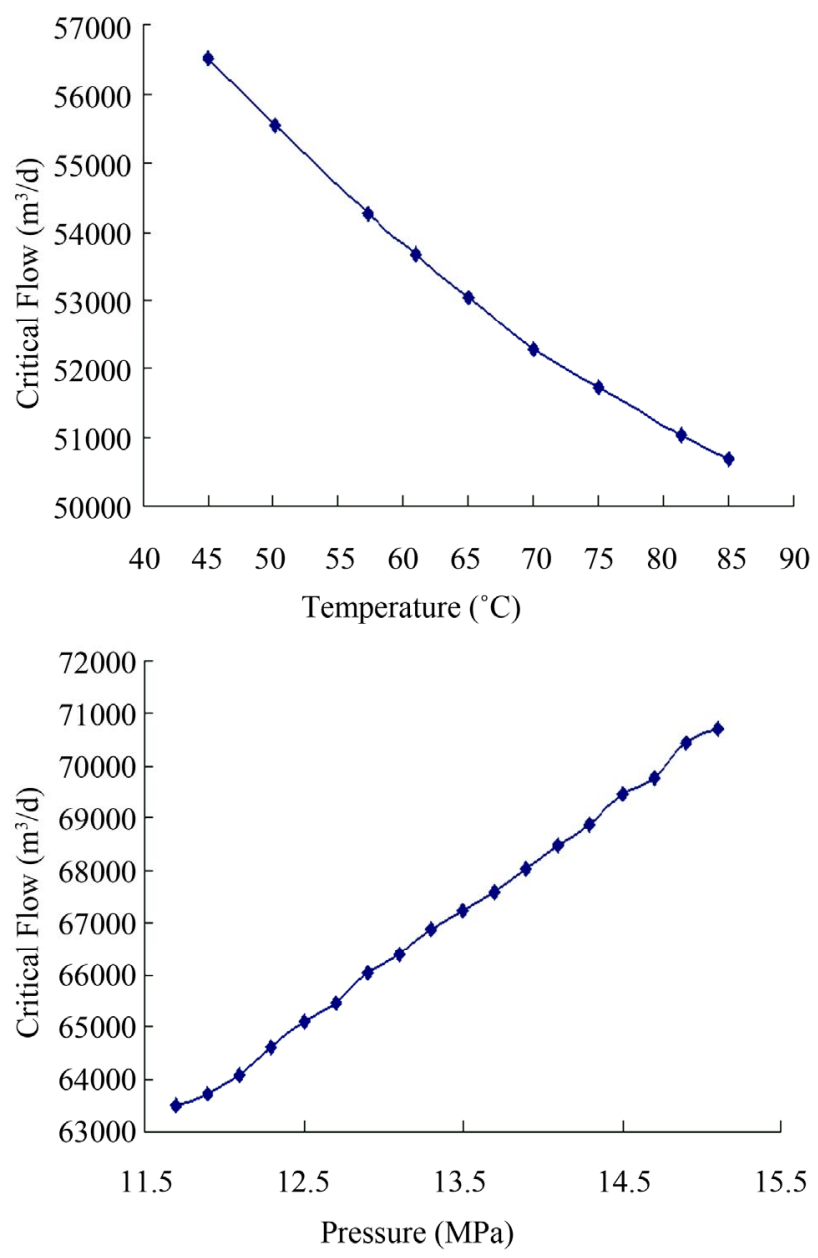

Figure 2. Reguler pattern of critical flow rate and critical flow velocity affect by temperature and pressure.

\subsection{Bottom Water Coning with Safety Prodction}

One of the main tasks of Bottom water drive gas reservoir engineering research is to determine the critical production and breakthrough time of the gas well [6], If the prorating production of the gas well is more than the critical production of the gas well, the well must be breakthrough, then when design reasonable production, take the critical production as a constraint, control its reasonable yield less than critical production, so as to realize the mining without water.

Bottom water coning critical production calculation formula:

$$
\begin{aligned}
& a^{\prime \prime}=\left(\frac{r_{e}}{h}\right)\left(\frac{k_{v}}{k_{h}}\right)^{0.5} \\
& q_{c}^{*}=0.7311+1.94341 / a^{\prime \prime} \\
& q_{s c}=\frac{0.8467 K_{h} h^{2} \Delta \rho_{w g}}{\mu_{g} B_{g}} q_{c}^{*}
\end{aligned}
$$

\section{Mine Field Example}

Above all comprehensive plan of proration production, combine with oil well outwater dynamic analysis, use the theory of the comprehensive factors to deter me the final match production plan of the gas well with corresponding gas block (see Table 1).

\section{Conclusion and Understanding}

1) The volcanic reservoir heterogeneity is extremely strong, and the relationship between gas and water is complex, gas well with the general policy in reasonable should be "for hole and appropriate, take into account the global”.

2) Make the single well with reasonable production principle, that is, based on the single well control reserves, it should get the speed of recovery balance. According to the productivity equation, relative to the energy, it should get to the pressure drop balance. According to the system analysis of gas well node, make full use of the formation energy reasonable [7]. With the requirements of the liquid is greater than the minimum yield, avoiding bottom effusion as far as possible; Less than bottom water coning critical production, prevent bottom water coning cracks along the high angle to the bottom; According to the dynamic analysis results of gas well water, adjust the yield, slow down the output of the water.

3) In this paper, the study is for the deep gas of $x u$ multi-factors comprehensive method with production, considering the open-flow capacity, gas speed equilibrium, pressure drop balanced, energy reasonable be used, liquid security, bottom water coning and so on. It is a more sci- 
Table 1. Proration production under multi influential factors $\left(10^{4} \mathrm{~m}^{3}\right)$.

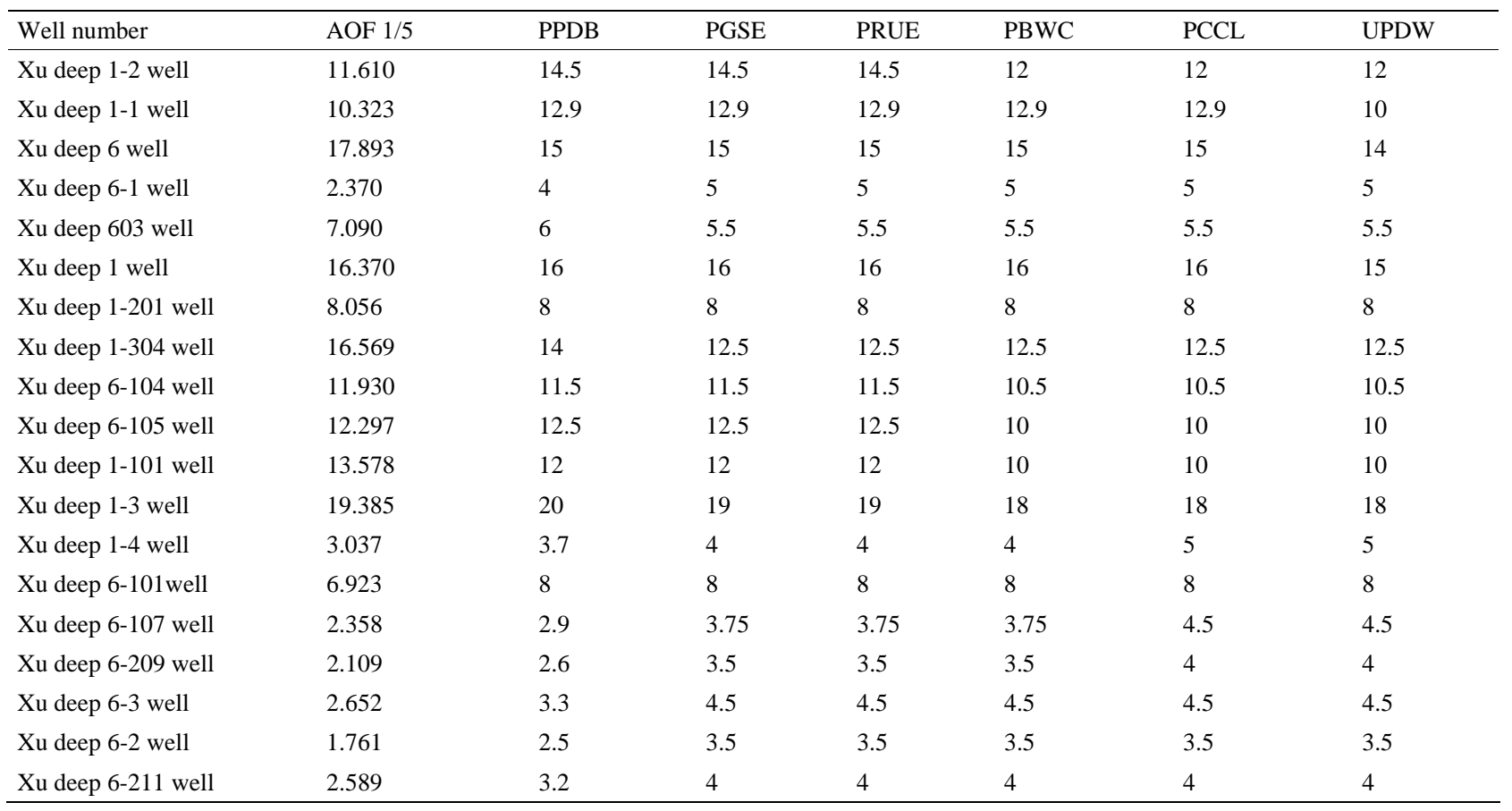

Open-flow capacity (AOF); Prorating production with pressure drop of balance (PPDB); Prorating production with Gas speed equilibrium (PGSE); Prorating production with Rational use of energy (PRUE); Prorating production with Bottom water coning (PBWC); Prorating production with carry critical liquid flow (PCCL); Ultimate prorating production with dynamicwater (UPDW).

entific and reasonable method, make the gas well production tends to optimization. According to match production results, The daily output of Xu block 19 Wells deep gas scale is $164 \times 10^{4} \mathrm{~m}^{3}$, The daily output of average single well gas is $8.631579 \times 10^{4} \mathrm{~m}^{3}$.

\section{REFERENCES}

[1] P. Shu, X. M. Bi, R. X. Ding, et al., "Xu Deep Volcanic Gas Reservoirs Gas Well Productivity Features and the controlling Factor Analysis," China Science and Technology Information, Vol. 15, No. 3, 2009, pp. 28-30.

[2] J. A. Carrall and R. N. Horne, "Multivariate Optimization of Production Systems," Journal of Petroleum Technology, Vol. 44, No. 7, 1992, pp. 782-789.

[3] H. I. Meyer and A. O. Garder, "Mechanics of Two Im- miscible Fluids in Porous Media," Journal of Applied Physics, Vol. 25, No. 11, 1954, pp. 1400-1406. doi:10.1063/1.1721576

[4] L. Yang, Y. Dong, Y. Huang, et al., "Low Permeability Sandstone Reservoir Gas Well Research on Prorating Production Method," Technology Supervision in Petroleum Industry, Vol.1 , No. 5, 2005, pp. 125-126.

[5] S. L. Qiu, “Xu Deep Gas Reservoirs Deep Volcanic Rock Gas Well Research of Decrease Degree,” Master's Thesis, Daqing Petroleum College, 2008.

[6] C. Bournazel and B. Jeanson, "Fast Water-Coning Evaluation Method," The SPE 46th Annual Fall Meeting, New Orleans, 3-6 October 1971, pp. 1-9.

[7] L. Z. Lu, "Gas Well and Gas Reservoir Optimization Method with Research and Production Software System Design,” Ph.D. Thesis, Southwest Petroleum Institute, 2005. 